\title{
Catalyst-Controlled Regio- and Stereoselective Bromolactonization with Chiral Bifunctional Sulfides
}

\section{Ayano Tsuchihashi} Seiji Shirakawa*

Department of Environmental Science, Graduate School of Fisheries and Environmental Sciences, Nagasaki University, 114, Bunkyo-machi, Nagasaki 852-8521, Japan

seijishirakawa@nagasaki-u.ac.jp

Published as part of the Cluster Organosulfur and Organoselenium Compounds in Catalysis

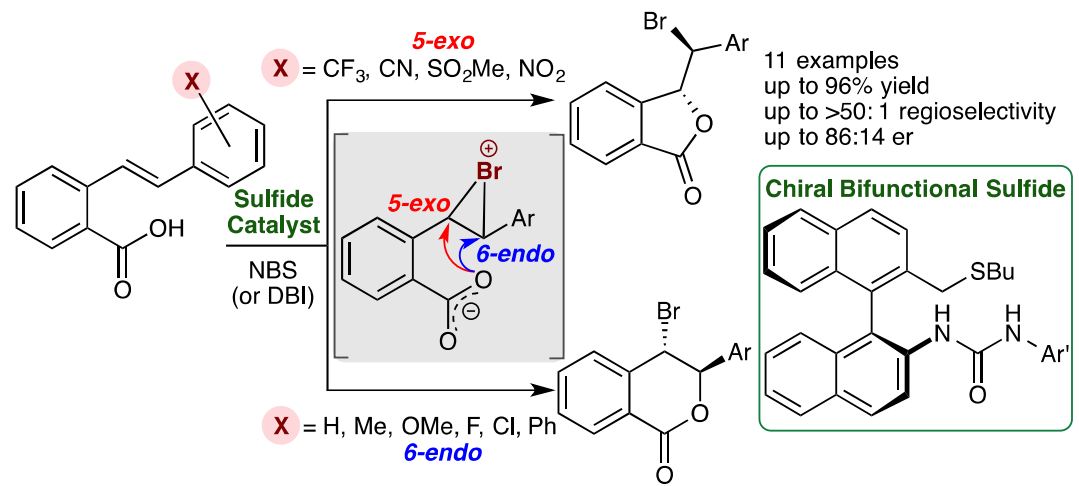

we report a catalyst-controlled regio- and stereoselective 5-exo bromolactonization of $\mathbf{1}$ with bifunctional chiral sulfides (S)-4.

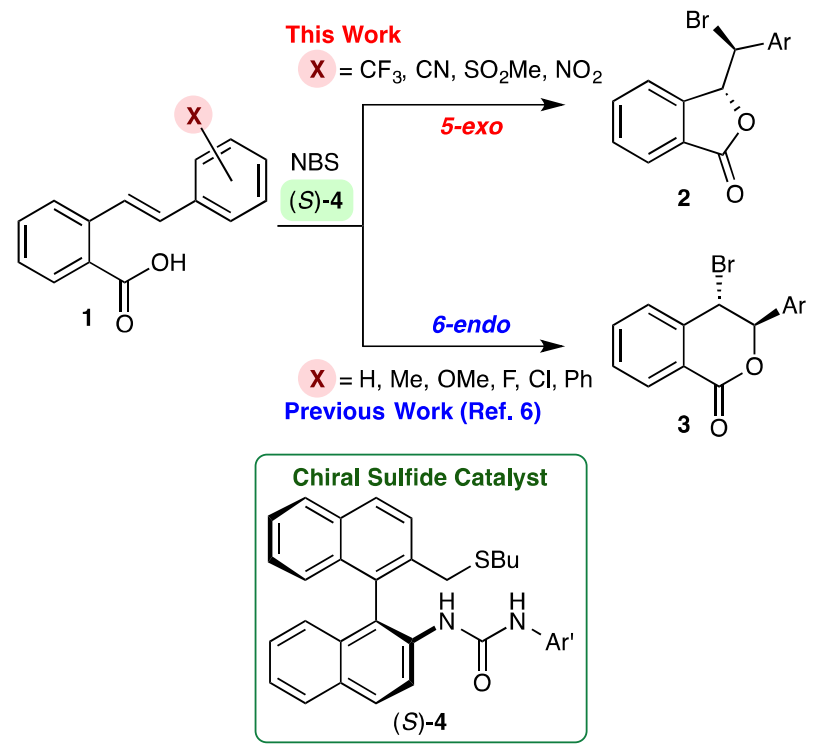

Scheme 1 Bifunctional sulfide-catalyzed asymmetric bromolactonizations of stilbene-type carboxylic acids 1 .

Asymmetric bromolactonization of $\mathbf{1 a}$ possessing a trifluoromethyl group was selected as a model reaction in an attempt to develop an effective catalyst for 5-exo-selective cyclization. Yeung reported that the 5-exo cyclization product 2a was preferentially obtained in the bromolactonization of $\mathbf{1 a}$ with or without catalysts in low to moderate regioselectivities (2a:3a $=2: 1-4: 1) \cdot{ }^{5}$ Our original aim was to improve regioselectivity via the use of bifunctional sulfide catalysts $(S)-4$ (Table 1). An attempted reaction of $\mathbf{1 a}$ with $\mathrm{N}$ bromosuccinimide (NBS) in $\mathrm{CH}_{2} \mathrm{Cl}_{2}$ under the influence of a phenylurea-type bifunctional catalyst $(S)-\mathbf{4 a}$ at $0{ }^{\circ} \mathrm{C}$ for $24 \mathrm{~h}$ provided bromolactonization product $\mathbf{2 a}$ in a good yield with moderate levels of regio- and enantioselectivity (Table 1, entry 
1). Encouraged by this result, a fine-tuning of the urea moiety on catalyst (S)-4 was performed to improve the regioselectivity. Although the introduction of arylurea possessing electrondonating groups on the catalyst $(\mathbf{4 b})$ caused a reduction in regioselectivity (Table 1 , entry 2 ), catalysts bearing electrondeficient arylureas (4c and $\mathbf{4 d}$ ) improved the levels of both regio- and enantioselectivity (Table 1, entries 3 and 4). A higher level of regioselectivity was observed in a reaction with catalyst $(S)$-4d (Table 1, entry 4). To establish the importance of the urea moiety on catalysts $(S)-\mathbf{4}$, we also examined the reactions with related BINOL-derived catalysts $(S)-\mathbf{5 a}$ and $\mathbf{5 b}$. Although these catalysts promoted the bromolactonization of $\mathbf{1 a}$, the 5exo cyclization product was obtained only in low levels of regioand enantioselectivity (Table 1, entries 5 and 6). Additionally, the reaction without a catalyst slowly proceeded under the reaction conditions with low regioselectivity (Table 1, entry 7). These results clearly suggested that a urea moiety of catalysts (S)-4 was essential to obtaining good levels of regio- and enantioselectivity in the present 5 -exo bromolactonization. ${ }^{9}$

\section{Table 1 Catalyst Optimization ${ }^{\mathrm{a}}$}

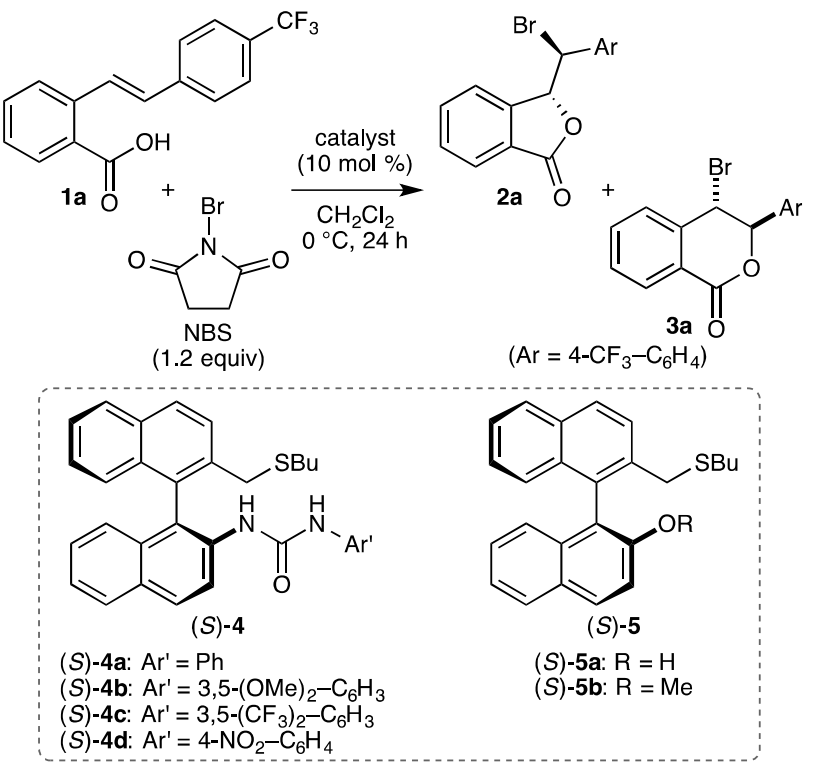

\begin{tabular}{|c|c|c|c|c|}
\hline Entry & Catalyst & $\begin{array}{l}\text { Regioselectivity } \\
\text { (2a:3a) }\end{array}$ & $\begin{array}{l}\text { Yield of 2a } \\
(\%)^{c}\end{array}$ & er of $2 a^{d, e}$ \\
\hline 1 & $(S)-\mathbf{4 a}$ & 5.3: 1 & 76 & $76: 24$ \\
\hline 2 & $(S)-\mathbf{4} \mathbf{b}$ & $3.2: 1$ & 67 & $75: 25$ \\
\hline 3 & $(S)-4 c$ & 7.1: 1 & 84 & $82: 18$ \\
\hline 4 & $(S)-\mathbf{4 d}$ & $8.5: 1$ & 86 & $82: 18$ \\
\hline 5 & $(S)-\mathbf{5 a}$ & 2.3: 1 & 59 & 49:51 \\
\hline 6 & $(S)-\mathbf{5 b}$ & 1.1: 1 & 39 & $50: 50$ \\
\hline 7 & nonef $^{f}$ & 1.8: 1 & 7 & $(50: 50)$ \\
\hline
\end{tabular}

${ }^{a}$ Reaction conditions: 1a $(0.10 \mathrm{mmol})$, NBS $(0.12 \mathrm{mmol})$, catalyst $(10 \mathrm{~mol} \%$, $0.010 \mathrm{mmol}), \mathrm{CH}_{2} \mathrm{Cl}_{2}(2.0 \mathrm{~mL}), 0{ }^{\circ} \mathrm{C}, 24 \mathrm{~h}$.

b Regioselectivities were confirmed via ${ }^{1} \mathrm{H}$ NMR analysis of the crude reaction mixture.

${ }^{c}$ Yield of isolated product $\mathbf{2 a}$.

${ }^{d}$ Determined by HPLC analysis on a chiral stationary phase.

e Enantioselectivities of product 3a were low (lower than 59:41 er).

${ }^{\mathrm{f}}$ The reaction was performed without a catalyst.
We also examined the effect of brominating reagents under the influence of optimized catalyst (S)-4d (Table 2). The levels of regio- and enantioselectivity for product 2a significantly depend on the structure of the brominating reagents. Reactions with brominating reagents possessing 5and 6-membered ring structures generally gave the target 5-exo cyclization product 2a in good to high levels of regioselectivity with moderate to good levels of enantioselectivity (Table 2, entries 1-4). On the other hand, $N$-bromoacetamide (NBA) as an acyclic brominating reagent gave product $\mathbf{2 a}$ with lower levels of regio- and enantioselectivity (Table 2, entry 5). Interestingly, the 6-endo cyclization product $\mathbf{3 a}$ was obtained in good regioselectivity when the reaction was performed with bromine $\left(\mathrm{Br}_{2}\right)$ as a brominating reagent, although almost no enantioselectivity was observed ( 50:50 er, Table 2 , entry 6$).{ }^{10}$ Among these brominating reagents, the highest level of regioselectivity for 2a was observed with dibromoisocyanuric acid (DBI), and the highest levels of enantioselectivity were achieved with NBS and DBI (Table 2, entries 1 and 4). ${ }^{11}$

Table 2 Effect of Brominating Reagents ${ }^{\mathrm{a}}$<smiles>[Y20]C(=O)OC(=O)c1ccccc1/C=C/c1ccc(C(F)(F)F)cc1</smiles><smiles>O=C1OC(Br)[C@H](Br)c2ccccc21</smiles><smiles>O=C1CCC(=O)N1Br</smiles>

NBS<smiles></smiles><smiles>CC1(C)C(=O)N(Br)C(=O)N1Br</smiles>
$\mathrm{DBH}$<smiles>CC(C)(C)NC(=O)NBr</smiles>

NBA

\begin{tabular}{lllll}
\hline Entry & X-Br & $\begin{array}{l}\text { Regioselectivity } \\
(2 \mathbf{a}: 3 a)\end{array}$ & $\begin{array}{l}\text { Yield of 2a } \\
(\%)^{c}\end{array}$ & er of 2a $^{\mathrm{d}, \mathrm{e}}$ \\
\hline 1 & NBS & $8.5: 1$ & 86 & $82: 18$ \\
2 & NBP & $13: 1$ & 90 & $71: 29$ \\
3 & DBH & $15: 1$ & 89 & $80: 20$ \\
4 & DBI & $18: 1$ & 92 & $82: 18$ \\
5 & NBA & $3.3: 1$ & 71 & $70: 30$ \\
6 & $\mathrm{Br}_{2}$ & $1: 11$ & $8(77)^{\mathrm{f}}$ & $50: 50$
\end{tabular}

${ }^{a}$ Reaction conditions: 1a $(0.10 \mathrm{mmol})$, brominating reagent $(0.12 \mathrm{mmol})$, catalyst (S)-4d (10 mol \%, $0.010 \mathrm{mmol}), \mathrm{CH}_{2} \mathrm{Cl}_{2}(2.0 \mathrm{~mL}), 0{ }^{\circ} \mathrm{C}, 24 \mathrm{~h}$.

b Regioselectivities were confirmed via ${ }^{1} \mathrm{H}$ NMR analysis of the crude reaction mixture.

${ }^{c}$ Yield of isolated product $\mathbf{2 a}$.

${ }^{d}$ Determined by HPLC analysis on a chiral stationary phase.

e Enantioselectivities of product 3a were low (lower than 59:41 er).

${ }^{\mathrm{f}}$ The yield in parenthesis refers to the isolated yield for product $\mathbf{3 a}$. 

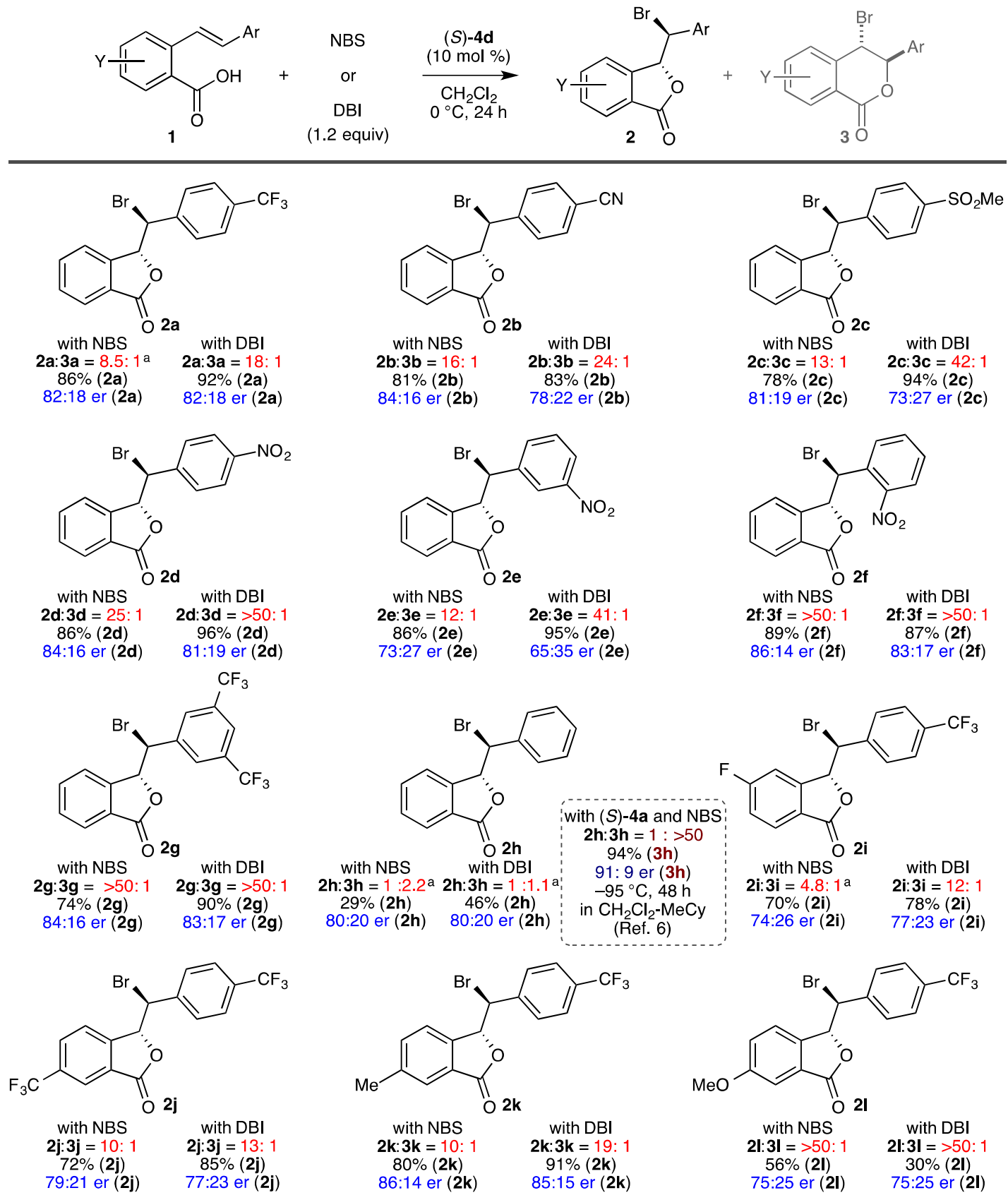

with NBS with DBI

2f: $\mathbf{3 f}=>50: 1 \quad$ 2f: $\mathbf{3 f}=>50: 1$

$86: 14$ er (2f)

$87 \%(2 f)$
$87 \%$ :

73:27 er (2e) 65:35 er (2e)

$83: 17$ er (2f)

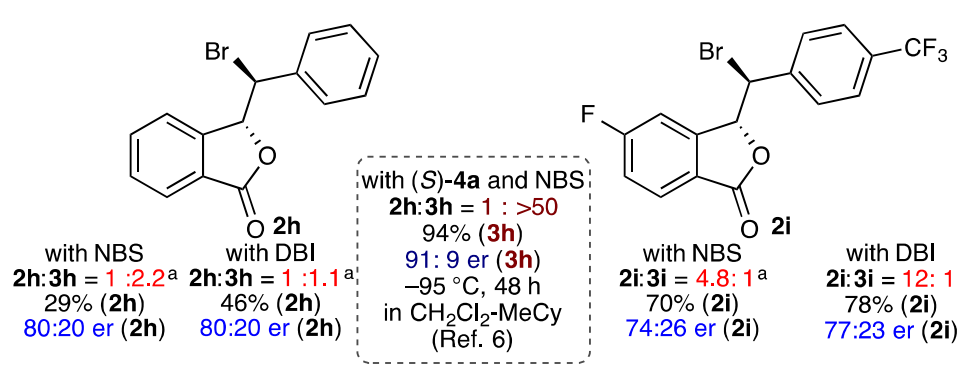

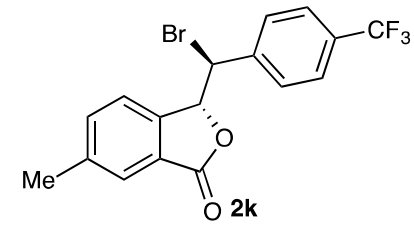

with NBS

2k:3k = 10: 1

$80 \%(2 \mathbf{k})$

with DBI

2k:3k = 19: 1

$91 \%(\mathbf{2 k})$

$85: 15$ er (2k)

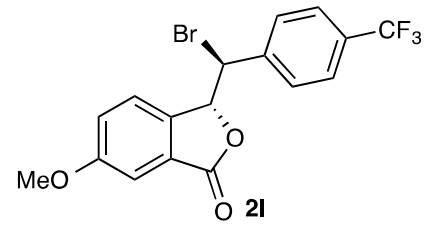

with NBS

2l: $3 \mathbf{l}=>50:$

$56 \%(21)$

with DBI

II:3I = >50:

$75: 25$ er (2l)

Scheme $\mathbf{2}$ Substrate scope. ${ }^{\text {a }}$ Enantioselectivities of products $\mathbf{3}$ were low (lower than 59:41 er). 
With the optimial catalyst $(S)-\mathbf{4 d}$ and reaction conditions in hand, we studied substrate generality for the 5exo-selective bromolactonization of $\mathbf{1}$ (Scheme 2).12 Both NBS and DBI were examined as possible brominating reagents that could provide generality in each substrate. First, we investigated the effect that an electron-withdrawing group (EWG) would exert on an aromatic ring (Ar) at the para-position of $\mathbf{1}$. The application of stilbene-type carboxylic acids 1 bearing a variety of EWGs produced highly regioselective reactions and products 2a-d in moderate to good levels of enantioselectivity. In general, the reactions with DBI provided higher levels of regioselectivity with slightly lower levels of enantioselectivity than those of the reactions with NBS. The reactions of $\mathbf{1}$ that possessed EWGs at the meta- and ortho-positions were also examined, and products 2e-g were obtained with high levels of regioselectivity. On the other hand, the reactions with simple substrate $\mathbf{1 h}(\mathrm{Ar}=\mathrm{Ph})$ without EWG produced bromolactonization products $\mathbf{2 h}$ and $\mathbf{3 h}$ with low levels of regioselectivity, and 6-endo cyclization product $\mathbf{3 h}$ was a major product even under the optimal reaction conditions for 5-exo cyclization. It should be noted that a complete regioselective reaction to produce $3 \mathbf{h}$ in a highly enantioselective manner was achieved with catalyst (S)-4a under low reaction temperature conditions. ${ }^{6}$ These opposite trends in regioselectivity could be explained by the nature of the substrates (Figure 1). When the reaction was performed with a simple substrate, $\mathbf{1 h}(\mathrm{Ar}=\mathrm{Ph})$, 6-endo cyclization was favored due to stabilization of the cationic nature on the benzylic carbon of the phenyl group (A in Figure 1). On the other hand, the introduction of EWG on the aryl moiety (Ar) destabilized the cationic nature on the benzylic carbon. As a result, 5-exo cyclization was favored slightly more than 6-endo cyclization (B in Figure 1). This trend for the production of 5-exo bromolactonization products 2 was enhanced by the reactions using urea-type bifunctional sulfide catalysts $(S)-\mathbf{4}$, due to the formation of a well-organized intermediate (C in Figure 1). ${ }^{6}$ The substituent effects on the other aromatic ring $(\mathrm{Y})$ of $\mathbf{1}$ were also examined to produce 2i-l (Scheme 2). Even with the introduction of EWGs to another aromatic ring (Y), the reactions proceeded with good levels of regioselectivity to give $\mathbf{2 i}$ and $\mathbf{2 j}$. The products $\mathbf{2 k}$ and $\mathbf{2 l}$ possessed electron-donating groups and were obtained in good levels of regio- and enantioselectivity.

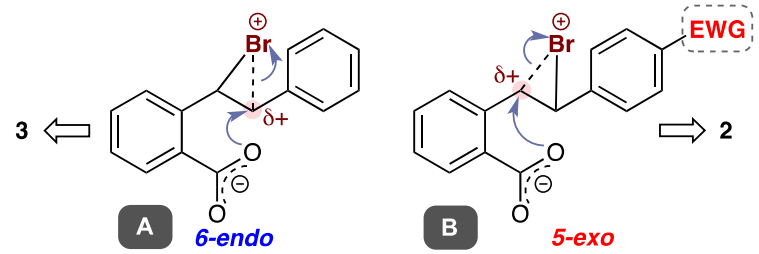

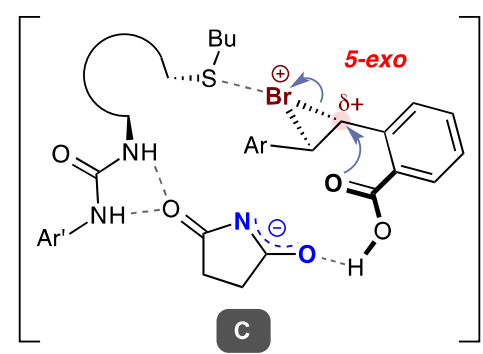

Figure 1 Cyclization steps

In summary, we successfully achieved hitherto unknown highly regioselective 5-exo bromolactonizations of stilbene-type carboxylic acids $\mathbf{1}$ bearing EWGs under the influence of urea-type chiral bifunctional sulfide catalysts $(S)-4$. The target chiral phthalide products 2 were obtained with moderate to good levels of enantioselectivity. The bifunctional design of catalysts $(S)$-4 with a urea moiety was essential in obtaining good levels of regio- and enantioselectivity for the proposed 5-exo bromolactonization.

\section{Funding Information}

This work was supported by JSPS KAKENHI Grant Number JP19K05480, the Cooperative Research Program of "Network Joint Research Center for Materials and Devices" (20191310), Tokuyama Science Foundation, Takahashi Industrial and Economic Research Foundation, and Shorai Foundation for Science and Technology.

\section{Supporting Information}

Supporting Information for this article is available online at https://doi.org/10.1055/s-

\section{References and Notes}

(1) For reviews on organocatalysis, see: (a) Dalko, P. I.; Moisan, L. Angew. Chem. Int. Ed. 2001, 40, 3726. (b) Dalko, P. I.; Moisan, L. Angew. Chem. Int. Ed. 2004, 43, 5138. (c) MacMillan, D. W. C. Nature 2008, 455, 304. (d) Comprehensive Enantioselective Organocatalysis: Catalysts, Reactions, and Applications, Dalko, P. I., Ed.; Wiley-VCH: Weinheim, 2013.

(2) For reviews on chiral sulfide catalysts, see: (a) Aggarwal, V. K. Synlett 1998, 329. (b) Aggarwal, V. K.; Winn, C. L. Acc. Chem. Res. 2004, 37, 611. (c) McGarrigle, E. M.; Myers, E. L.; Illa, O.; Shaw, M. A.; Riches, S. L.; Aggarwal, V. K. Chem. Rev. 2007, 107, 5841. (d) Gómez Arrayás, R.; Carretero, J. C. Chem. Commun. 2011, 47, 2207. (e) Luo, J.; Liu, X.; Zhao, X. Synlett 2017, 28, 397.

(3) For recent examples of chiral sulfide catalysts, see: (a) Wu, H.-Y.; Chang, C.-W.; Chein, R.-J. J. Org. Chem. 2013, 78, 5788. (b) Ke, Z.; Tan C. K.; Chen, F.; Yeung, Y.-Y. J. Am. Chem. Soc. 2014, 136, 5627. (c) Ke, Z.; Tan, C. K.; Liu, Y.; Lee, K. G. Z.; Yeung, Y.-Y. Tetrahedron 2016, 72, 2683. (d) Liu, X.; An, R.; Zhang, X.; Luo, J.; Zhao, X. Angew. Chem. Int. Ed. 2016, 55, 5846. (e) Li, Q.-Z.; Zhang, X.; Zeng, R.; Dai, Q.-S.; Liu, Y.; Shen, X.-D.; Leng, H.-J.; Yang, K.-C.; Li, J.-L. Org. Lett. 2018, 20, 3700. (f) Cao, Q.; Luo, J.; Zhao, X. Angew. Chem. Int. Ed. 2019, 58, 1315. (g) 
Okada, M.; Kaneko, K.; Yamanaka, M.; Shirakawa, S. Org. Biomol. Chem. 2019, 17, 3747

(4) For reviews on catalytic asymmetric halolactonization, see: (a) Chen, G.; Ma, S. Angew. Chem. Int. Ed. 2010, 49, 8306. (b) Tan, C. K.; Zhou, L.; Yeung, Y.-Y. Synlett 2011, 1335. (c) Castellanos, A.; Fletcher, S. P. Chem. Eur. J. 2011, 17, 5766. (d) Denmark, S. E.; Kuester, W. E.; Burk, M. T. Angew. Chem. Int. Ed. 2012, 51, 10938. (e) Hennecke, U. Chem. Asian J. 2012, 7, 456. (f) Tan, C. K.; Yeung, Y.-Y. Chem. Commun. 2013 49, 7985. (g) Murai, K.; Fujioka, H. Heterocycles 2013, 87, 763. (h) Tan, C. K.; Yu, W. Z.; Yeung, Y.-Y. Chirality 2014, 26, 328. (i) Zheng, S.; Schienebeck, C. M.; Zhang, W.; Wang, H.-Y.; Tang, W. Asian J. Org. Chem. 2014, 3, 366. (j) Cheng, Y. A.; Yu, W. Z.; Yeung, Y.-Y. Org. Biomol. Chem. 2014, 12, 2333. (k) Tripathi, C. B.; Mukherjee, S. Synlett 2014, 25, 163. (I) Sakakura, A.; Ishihara, K. Chem. Rec. 2015, 15, 728. (m) Gieuw, M. H.; Ke, Z.; Yeung, Y.-Y. Chem. Rec. 2017, 17, 287. (n) Kawato, Y.; Hamashima, Y. Synlett 2018, 29, 1257. (o) Kristianslund, R.; Tungen, J. E.; Hansen, T. V. Org. Biomol. Chem. 2019, 17, 3079.

(5) (a) Chen, J.; Zhou, L.; Tan, C. K.; Yeung, Y.-Y. J. Org. Chem. 2012, 77, 999. (b) Chen, T.; Yeung, Y.-Y. Org. Biomol. Chem. 2016, 14, 4571.

(6) Nishiyori, R.; Tsuchihashi, A.; Mochizuki, A.; Kaneko, K.; Yamanaka, M.; Shirakawa, S. Chem. Eur. J. 2018, 24, 16747.

(7) For reviews on phthalides, see: (a) Beck, J. J.; Chou, S.-C. J. Nat. Prod. 2007, 70, 891. (b) Karmakar, R.; Pahari, P.; Mal, D. Chem. Rev. 2014, $114,6213$.

(8) For examples of catalytic asymmetric synthesis of chiral phthalides, see: (a) Kitamura, M.; Ohkuma, T.; Inoue, S.; Sayo, N.; Kumobayashi, H.; Akutagawa, S.; Ohta, T.; Takaya, H.; Noyori, R. J. Am. Chem. Soc. 1988, 110, 629. (b) Everaere, K.; Scheffler, J.-L.; Mortreux, A.; Carpentier, J.-F. Tetrahedron Lett. 2001, 42, 1899. (c) Lei, J.-G.; Hong, R.; Yuan, S.-G.; Lin, G.-Q. Synlett 2002, 927. (d) Tanaka, K.; Nishida, G.; Wada, A.; Noguchi, K. Angew. Chem. Int. Ed. 2004, 43, 6510. (e) Chang, H.-T.; Jeganmohan, M.; Cheng, C.-H. Chem. Eur. J. 2007, 13, 4356. (f) Tanaka, K.; Osaka, T.; Noguchi, K.; Hirano, M. Org. Lett. 2007, 9, 1307. (g) Luo, J.; Wang, H.; Zhong, F.; Kwiatkowski, J.; Xu, L.-W.; Lu, Y. Chem. Commun. 2012, 48, 4707. (h) Zhong, F.; Luo, J.; Chen, G.-Y.; Dou, X.; Lu, Y. J. Am. Chem. Soc. 2012, 134, 10222. (i) Luo, J.; Jiang, C.; Wang, H.; Xu, L.-W.; Lu, Y. Tetrahedron Lett. 2013, 54, 5261. (j) Luo, J.; Wang, H.; Zhong, F.; Kwiatkowski, J.; Xu, L.-W.; Lu, Y. Chem. Commun. 2013, 49, 5775. (k) Liu, R.; Jin, R.; An, J.; Zhao, Q.; Cheng, T.; Liu, G. Chem. Asian J. 2014, 9, 1388. (I) Han, X.; Dong, C.; Zhou, H.B. Adv. Synth. Catal. 2014, 356, 1275. (m) Parmar, D.; Maji, M. S. Rueping, M. Chem. Eur. J. 2014, 20, 83; (n) Egami, H.; Asada, J.; Sato,
K.; Hashizume, D.; Kawato, Y.; Hamashima, Y. J. Am. Chem. Soc. 2015 137, 10132. (o) Gelat, F.; Coffinet, M.; Lebrun, S.; AgbossouNiedercorn, F.; Michon, C.; Deniau, E. Tetrahedron: Asymmetry 2016, 27, 980. (p) Kong, L.; Zhao, J.; Cheng, T.; Lin, J.; Liu, G. ACS Catal. 2016, 6, 2244. (q) Liu, W.; Hu, Z.-P.; Yan, Y.; Liao, W.-W. Tetrahedron Lett. 2018, 59, 3132. (r) Cabrera, J. M.; Tauber, J.; Krische, M. J. Angew. Chem. Int. Ed. 2018, 57, 1390.

(9) The reaction with catalyst (S)-4d at low temperature, and the reaction with another different catalyst, see Schemes S1 and S2 in Supporting Information.

(10) The reaction with bromine $\left(\mathrm{Br}_{2}\right)$ may proceed via non-catalyzed reaction pathway (background reaction pathway). The reaction using another reactive brominating reagent, see Scheme S3 in Supporting Information.

(11) Other control experiments, see Scheme S4 in Supporting Information.

(12) General Procedure for Asymmetric Bromolactonizations

To a solution of substrate $\mathbf{1}(0.10 \mathrm{mmol})$ and catalyst (S)-4d (10 mol \%, $0.010 \mathrm{mmol})$ in $\mathrm{CH}_{2} \mathrm{Cl}_{2}(2.0 \mathrm{~mL})$ was cooled to $0{ }^{\circ} \mathrm{C}$. After stirring for 10 min at $0{ }^{\circ} \mathrm{C}, \mathrm{N}$-bromosuccinimide (NBS) $(0.12 \mathrm{mmol})$ was added to the cooled reaction solution. The reaction mixture was stirred for $24 \mathrm{~h}$ at $0{ }^{\circ} \mathrm{C}$. After $24 \mathrm{~h}$, the reaction mixture was quenched with saturated aqueous $\mathrm{Na}_{2} \mathrm{SO}_{3}(4.0 \mathrm{~mL})$ at $0{ }^{\circ} \mathrm{C}$ and stirred for $10 \mathrm{~min}$ at $0{ }^{\circ} \mathrm{C}$. The quenched reaction mixture was diluted with $\mathrm{CH}_{2} \mathrm{Cl}_{2}(2 \mathrm{~mL})$ and $\mathrm{H}_{2} \mathrm{O}(2$ $\mathrm{mL}$ ), and warmed to room temperature. The organic materials were extracted with $\mathrm{CH}_{2} \mathrm{Cl}_{2}$ for three times $(5.0 \mathrm{~mL} \times 3)$. The combined extracts were dried over $\mathrm{Na}_{2} \mathrm{SO}_{4}$ and concentrated. [The ${ }^{1} \mathrm{H} \mathrm{NMR}$ analysis of the crude reaction mixture was performed at this stage to determine the regioselectivity of bromolactonization products.] The residue was purified by flash column chromatography on silica gel (hexane/ethyl acetate as eluent) to give product 2 . The enantioselectivity of the product $\mathbf{2}$ was determined by HPLC analysis on a chiral stationary phase.

2a: ${ }^{5}[\alpha]^{21} \mathrm{D}+4.4\left(c=0.87, \mathrm{CHCl}_{3}, 82: 18 \mathrm{er}\right.$ ); HPLC analysis: Daicel Chiralpak IC-3, hexane/2-propanol $=10: 1$, flow rate $=0.5 \mathrm{~mL} / \mathrm{min}, 230$ $\mathrm{nm}$; retention time: $59.3 \mathrm{~min}$ (major) and $68.8 \mathrm{~min}$ (minor). ${ }^{1} \mathrm{H} \mathrm{NMR}$ $\left(400 \mathrm{MHz}, \mathrm{CDCl}_{3}\right) \delta 7.85(\mathrm{~d}, J=7.2 \mathrm{~Hz}, 1 \mathrm{H}), 7.67-7.71(\mathrm{~m}, 2 \mathrm{H}), 7.53-$ $7.60(\mathrm{~m}, 5 \mathrm{H}), 5.96(\mathrm{~d}, J=6.4 \mathrm{~Hz}, 1 \mathrm{H}), 5.16(\mathrm{~d}, J=6.4 \mathrm{~Hz}, 1 \mathrm{H}) ;{ }^{13} \mathrm{C} \mathrm{NMR}$ $\left(100 \mathrm{MHz}, \mathrm{CDCl}_{3}\right) \delta 168.9,146.0,140.1,134.1,131.1(\mathrm{q}, J=32.1 \mathrm{~Hz})$, $130.2,129.0,126.5,126.0(\mathrm{q}, J=2.5 \mathrm{~Hz}), 125.7(\mathrm{~m}), 123.7,123.6$ (q, $J=$ $272 \mathrm{~Hz}$ ), 82.1, 51.8; IR (neat): 1769, 1324, 1286, 1167, 1124, 1114, $1067,1018 \mathrm{~cm}^{-1}$. 